\title{
Experimental Modal Analysis and Seismic Mitigation of Statue-Pedestal Systems
}

\author{
Christine E. Wittich, ${ }^{\mathrm{a}, \mathrm{c},}$, Tara C. Hutchinson ${ }^{\mathrm{b}, \mathrm{c}}$
}




\section{Abstract}

The seismic protection of cultural heritage, particularly statues, is a critical issue due to its high cultural significance, difficulty to repair or replace artifacts, and observed poor behavior during past earthquakes. Recent research has explored analysis techniques and methodologies for predicting the seismic response of statues; however, these studies typically assume the statue to be either freestanding or rigidly attached. The seismic response of statues with these different boundary conditions varies widely and therefore accurate characterization is critical. While modern mounting techniques aim to rigidly attach a statue to the floor or to a pedestal, the degree of rigidity of the asbuilt system may vary greatly, particularly for large and heavy statues, which are difficult to mount. To this end, experimental modal analysis and system identification were conducted on six statues while in their installed condition at the Asian Art Museum in San Francisco, California. The tested statues were large, typically stone, and restrained with different mechanisms for comparison. The statue-pedestal-restraint systems were observed to be quite flexible with natural frequencies as low as 3 Hz. However, certain systems, which incorporated an embedded base of the statue, were much stiffer with frequencies around $14 \mathrm{~Hz}$. It is noted that this type of testing requires significant contact and excitation of the statue. This rare opportunity to work directly with the statues resulted in a valuable dataset summarizing their dynamic characteristics for museum engineers and curators. In cases where rigidity is not attained, there is concern that the statue's natural frequency may be too close to that of the anticipated floor motions. For this reason, a simple and non-intrusive base isolation system is detailed. This system was further verified through shake table testing and is shown to sufficiently reduce earthquake demands to the statue.

\section{Keywords: $\quad$ system identification/museum contents/statue/experimental modal analysis/seismic isolation/cultural heritage}

\section{Research Aims}

The aim of this research was to quantify the dynamic characteristics of typical statue-pedestal systems which incorporate modern mounting techniques. While art objects are often intended to be fixed to their pedestal and/or the museum floor, the degree of rigidity of the constructed system is generally 
unknown. This variability can have a significant impact on the seismic response of the statue-pedestal while in their installed condition at the Asian Art Museum in San Francisco, California (USA). These statues were full-scale, typically stone, and incorporated various restraint systems. Experimental procedures, such as this, are very rarely allowed due to the full-contact nature of the testing; and, as such, this manuscript is not intended to provide a comprehensive methodology for the seismic assessment of any arbitrary statue. Rather, the dataset can be used for qualitative guidance on the dynamic characteristics of statue-pedestal systems with modern restraints. Furthermore, a simple seismic isolation system is presented, which can be incorporated for statues unable to achieve rigidity.

\section{Introduction}

The preservation and seismic protection of cultural heritage has become a particularly important focus of both the earthquake engineering and museum communities. Damage to cultural heritage, particularly large, human-form or other slender, heavy statues, can be particularly devastating because the artifacts are not only historically significant but also unique and irreplaceable. Moreover, catastrophic toppling or other excess movement may pose significant safety hazards during an earthquake. Damage to heritage statues has been observed repeatedly following earthquake events around the world, such as the 2009 L'Aquila (Italy) [1], 2014 South Napa (USA) [2], and the most recent 2015 Gorkha (Nepal) earthquakes [3]. As a result, it is critical to understand how the statues interact with their pedestals and restraint systems when subject to earthquakes. Provided this understanding, seismic mitigation methods can be proposed and implemented in an effort to protect cultural heritage.

Due to the importance of heritage protection, numerous studies have been presented in the literature focusing on the prediction of the seismic response of statues. To the authors' knowledge, the earliest, most profound major study in this area was conducted at the J. Paul Getty Museum in Los Angeles, California (USA) [4]. In this study, the seismic vulnerability of the museum contents was determined based on rigid body dynamics and estimated geometric properties. More recently, a multidisciplinary diagnostic analysis of Michelangelo's David was conducted to assess the current state of 
health of the statue [5]. While the investigation focused on understanding the existing crack 


\section{Description of Museum and Statues Tested}

Testing of six statues was conducted on-site at the Asian Art Museum in San Francisco, California, in October 2014. San Francisco is a region of particularly high seismicity and therefore special attention is needed to protect the museums and their contents. This particular museum building is a historic, three-story structure, which was originally the San Francisco Old Main Library. The building was heavily damaged in the 1989 Loma Prieta earthquake and subsequently underwent significant seismic retrofitting and base isolation prior to becoming the home of the museum. Design and analysis of the retrofit of the building, by Forell/Elsesser Engineers, indicates the newly base isolated building would have a period of 2.4 seconds (frequency of $0.42 \mathrm{~Hz}$ ), dramatically protecting it from damaging earthquake motions [9].

The museum's primary collections include both modern art and ancient archaeological artifacts from all areas of Asia. In addition to these collections, at the time of this study, the museum was host to the Roads of Arabia exhibition sponsored by the Smithsonian Institute. This exhibition contained hundreds of pre-Islamic artifacts from Saudi Arabia. Six total statues were tested with three from the primary collections and three from the Roads of Arabia exhibit (Colossi statues). The three Colossi statues were chosen due to their cultural significance, size, and weight. The three statues from the primary galleries were chosen due to their unique restraint systems, which in particular allowed a comparison to that of the Colossi. Similar to the Colossi, these statues are also considered quite significant and were also considered vulnerable by the museum due to their massive size and weight.

Historical and physical details of the selected statues are included in Table 1. Images of each of the statues and the statue restraint systems are included in Figs. 1 and 2, respectively. It is noted that each of the statues is monolithic and did not exhibit visible signs of damage, such as surface cracking or otherwise excessively deteriorated regions. The Colossi statues ranged in height from $1.9-2.4 \mathrm{~m}$ and are constructed of solid sandstone. These statues are restrained laterally using contoured arms, which surround the statue on roughly three sides at the approximate "waist" of the statue $(20-40 \%$ of the height of the statue; Fig. 2a-c). These arms are attached to a separate steel post to the pedestal upon which the statues rest. Due to the uneven bases of the statue, a molded foot was custom constructed for the statue to rest. The first of three primary gallery statues is a $2.2 \mathrm{~m}$ marble statue of 
the Chinese Bodhisattva. This statue has an embedded epoxy anchor approximately $0.3 \mathrm{~m}$ from its

\section{Experimental Modal Analysis}

Experimental modal analysis (EMA) is a technique used to determine the natural frequencies and modes of vibration of a structure. Similar to operational modal analysis, the process consists of measuring the acceleration of a structure at numerous points. In contrast to operational modal analysis, EMA provides a known input to excite the vibration of the structure and increases the signalto-noise ratio. While this input can be applied as harmonic input from a portable shaker or an impulse from an impact hammer, portable shakers may inadvertently excite other objects in the vicinity of the intended test specimen, in addition to the target. As a result, EMA with an impact hammer is the ideal choice for determining the natural frequencies of the as-built statue-pedestal-restraint systems. It should be noted that this technique not only requires multiple sensors to be in direct contact with the statue, but also requires contact at the point of impact of the hammer. For this reason, EMA is typically not permitted by museums and the analyses described in this paper are exceptionally rare.

\subsection{Test Setup and Procedure}

Due to the sensitive nature of testing culturally significant statues, the test setup is described in particular detail as it deviates from traditional structural monitoring. Images of a representative test setup are included in Fig. 3 for Colossi 112; however, sensor attachment and general sensor placement were consistent for all tests reported. Each statue was instrumented with seven small, lightweight, 
uniaxial accelerometers along the height of the statue as well as along any restraint system. The accelerometers are piezoelectric sensors with a dynamic range of $0.5-10,000 \mathrm{~Hz}$ at $500 \mathrm{~g}$. Firm attachment of the sensors is critical for direct measurement of the statue acceleration. However, use of harsh adhesives or drilling into the statue is clearly not permitted. As a result, the sensors were held in place by a rubber strap. In addition, to avoid introducing or removing any particulates from the surface of these artifacts, a polyethylene wrap was placed beneath the rubber straps with a small hole to allow only the sensor to come into contact with the statue. Where permitted, such as on the modern restraint system, magnetic tips were used to affix the sensors to the structure. A $0.90 \mathrm{~kg}$ modallytuned hammer was used to tap the statue and excite its natural frequencies. The hammer has a hard rubber tip to avoid localized surface damage. The force of the hammer and acceleration of the sensors were recorded by a laptop-controlled portable signal conditioning and data acquisition system. The testing procedure consisted of tapping the statue and recording the free vibration for 8 seconds. Each test was repeated five times. In an effort to identify all primary modes important for response during an earthquake, taps were applied in two orthogonal horizontal directions both at the top of the structure and at approximately mid-height. Due to the highly irregular geometry, it is recognized that the same modal frequencies may be identified following taps in each direction. However, the relative amplitude of the modal response will vary according to the direction.

\subsection{Data Processing}

To understand the vibrational response of the statues, the time histories of acceleration are transformed to the frequency domain via Fast Fourier Transform (FFT). The magnitude (absolute value) of the ratio of the FFT of the output (measurement on the statue) to that of the input (that on the hammer tip) is known as a Frequency Response Function (FRF), or more commonly via its short name as a transfer function. To increase the resolution of the transfer function, the FRF is taken as the average of the five trials of each test. Relative peaks in the final FRF indicate the presence of a natural frequency or mode. The mode is considered global if all of the sensors along the system align at the peak. If only a few of the sensors align at the peak, the mode would be considered local. The FRFs of all sensors for a representative test, corresponding to the setup of Colossi 112, are overlaid in Fig. 4. 
In this figure, each FRF clearly contains peaks at frequencies of $2.9 \mathrm{~Hz}$ and $4.1 \mathrm{~Hz}$ indicating global

\section{Results}

The goal of the modal analysis was to determine the lowest natural frequencies or modes of the constructed statue-pedestal-restraint systems, as these may be activated during an earthquake. Higher modes are not considered in this study because they are difficult to excite in testing due to the low amplitude excitation. The following test results are presented in terms of the two lowest observed natural frequencies or modes, $f_{1}$ and $f_{2}$, regardless of direction. Mode shapes are not presented for these frequencies, as they are not essential for the current test objectives. Furthermore, the imperfect surfaces did not allow the sensors to be in precisely the same direction. However, the modal data provide evidence that global modes involving the statue, pedestal, and restraint system exist as seen in Fig. 4. While each mode may have been more significantly excited due to impact in one direction, both modes were discernible when the statue was excited in either of two orthogonal horizontal directions at both the top of the statue and at mid-height.

\subsection{As-Built Restraint Systems}

A scatter plot of the two lowest natural frequencies (modes 1 and 2) of each of the statue-restraint systems is presented in Fig. 5. In this graphic, mode 1 is associated with the lowest observed natural frequency and mode 2 with the second lowest. Each of the plotted modes was observable when excited in either horizontal direction and is not associated with a specific axis of vibration. Both modes for each statue were less than $16.67 \mathrm{~Hz}$, which is a common lower bound identifying whether a system will behave rigidly during earthquake excitation [10]. It should be noted that the first bending mode associated with vibration of the fixed-base statues themselves would be an order of magnitude larger than the plotted frequencies, and the statues alone would be considered rigid. For example, a fixed-base Colossi 112 is estimated (via hand calculation and finite element analyses not presented herein) to have a natural frequency around $40 \mathrm{~Hz}$. This indicates that the experimentally measured frequencies are associated with a system-wide mode of the statue-pedestal-restraint system; and, that 


\subsection{Modified Restraint Systems}

Due to the relatively low natural frequencies associated with the first two modes of response for the Colossi statues, comparative tests with a loosened restraint system were performed on two of the Colossi statues. The primary restraint of these statues is provided by contoured steel arms, located at approximately one-third the statue height (i.e. waist of the statue), which were hand-tightened by the 
museum mountmaker (Fig. 2a-c). Prior to these comparative tests, the steel arms were loosened

\subsection{Comparison with Building Response}

The tested statues are observed to be fairly flexible with complex restraint systems. Therefore, statue-specific time history analyses may be difficult to accurately conduct, given the assumptions needed for modeling at the connections. Furthermore, the studied statues are housed in a base-isolated structure and would be subject to a strongly filtered earthquake motion. As a result, a simplified comparison of the statue-restraint systems to anticipated average building response is presented. The structural designers responsible for the seismic retrofit and base isolation of the Asian Art Museum generated acceleration spectra for the individual floors and wings of the building [9]. The mean spectrum was generated using earthquakes scaled to a probability of exceedance of $2 \%$ in 50 years. 
The spectrum presented in Fig. 7 is for the critical gallery floor, which is subject to the largest dynamic amplification. The lowest natural frequency (first mode) of each statue-pedestal-restraint system is overlaid on this spectrum such that an approximation of any amplification due to the flexibility of the construction can be determined.

Referring to the overlaid lines in Fig. 7, the primary gallery statues (i.e. Bodhisattva, Attendant, Rama) are sufficiently stiff such that very little amplification at low levels of acceleration is likely to occur. This implies that the acceleration of the museum floor that the statue is subject to would not be amplified by the vibration of the installed statue-pedestal-restraint system. This amplification (or lack thereof) is presented on the right axis of Fig. 7, which indicates the ratio of the pseudo-spectral acceleration at a given frequency to that at a frequency of zero (rigid). As such, the natural frequencies of the Colossi statues are observed to lie within a region of amplification. Due to the flexibility of the system, the Colossi statues would be subject to nearly $250 \%$ the acceleration of the museum floor. To this end, an alternative method for seismic mitigation is required to avoid potentially large amplitude displacement and acceleration demands.

\section{Seismic Isolation}

Seismic isolation, or colloquially termed base isolation, is an effective means of protecting structures from the damaging effects of earthquakes. In the present case, the historical building has been seismically retrofitted with lead-rubber bearing isolators placed between its foundation and the superstructure. Isolation of this type elongates the building's period (reduces the natural frequency). As a result, it is typically recommended to rigidly fix building contents to the floors as the contents are likely much stiffer, i.e. have frequencies much greater than that of the isolated building. However, certain contents, such as the Colossi statues in their installed condition, have natural frequencies that may result in amplification of seismic forces while on display. To overcome this, isolation at the statue-pedestal level can protect the statues from the floor level excitations anticipated during an earthquake.

Isolation systems are typically designed to elongate the period of the statue-pedestal system away from that of the building. Typical structural isolation (i.e. rubber bearings) is not applicable given the 
lightweight construction of the statues [11]. Alternative isolation systems targeted at smaller structures include friction-pendulum systems [12] and rolling systems [13]. However, these systems are still designed to shift the period of the statue-pedestal system requiring a statue-specific, and sometimes complex, design that is difficult to implement in a base-isolated building. An alternative system, which aims only to reduce the amplitude of seismic forces, is the flat sliding plate system. This system incorporates a low-friction interface beneath the pedestal; and, when subject to horizontal forces greater than its coefficient of friction, the system slides and the larger forces are not transferred to the statue. This system, therefore, also has the potential for large displacements during and after an earthquake, which typically limits its application. However, in this case, the sliding plate isolation system was selected, as the area around the statues was free of obstacles and the intent was to reduce the potential for large earthquake forces with limited frequency modification of the system.

\subsection{System Description}

The installed isolation system beneath the Colossi statues consisted of an assembly of low profile, low-friction sliding plates. This system is fitted to the width of the pedestal, less than a couple of millimeters in height, and is virtually invisible to patrons of the museum. Furthermore, this type of system is relatively simple for installation, as it does not require modification of the statue, the pedestal, or any restraints above the base. A schematic of this system as well as a close-up image beneath Colossi 111 are shown in Fig. 8. In addition to these pragmatic attributes of the system, a low-friction interface seismic isolation system is conceptually simple and easy to convey to the nonengineering members of the museum community. When subject to lateral loading, the acceleration transferred to the statue-pedestal-restraint system will be a fraction of that which would be achieved for a non-isolated system. This fraction is the coefficient of friction, which in the case of the Colossi statue isolation assembly is $2 \%$.

\subsection{Experimental Verification}

Prior to installation, the sliding plate system was tested on a uniaxial shake table with a representative pedestal and stiff statue-like structure. This experimental setup is shown in Fig. 8c 
juxtaposed with the installed system in Fig. 8b. The pedestal rested atop the same sliding plate isolation system that was installed beneath the Colossi, however it was characterized by an approximate coefficient of friction of $15 \%$. While other sliding isolation systems have been tested in the past, the installed system consisting of unattached corrugated and coated steel plates had not previously been tested under earthquake motions. It is also noted that the culturally significant nature of the real Colossi statues precluded their transportation and use during shake table testing; therefore, the stiff, statue-like structure was designed to capture the mass and geometry of the statues. In addition, it was further restrained to a pedestal, yielding a system that is dynamically similar to the Colossi.

A representative comparison is included in Fig. 9 for the response of the isolated and non-isolated systems subject to a motion from the 1999 Duzce earthquake recorded at Bolu station in Turkey, though the system was tested to a number of additional recorded motions (e.g. 1985 Valparaiso at USFM; 1989 Loma Prieta at Gavilan College; 1994 Northridge at UCLA). The motions used, including the Duzce motion as shown in Fig. 9, were selected due to the presence of long-period pulse content, which was anticipated to excite the response of both the pedestal and the statue-like specimen. The acceleration of the isolated and non-isolated pedestals is provided in Fig. 9 as both a time history and in the pseudo-spectral acceleration format. A significant reduction of amplitude for the isolated specimen is observed in both plots. However, the limited frequency modification is quite evident in the pseudo-spectral acceleration plot, which also includes that of the shake table (input). Moreover, in this plot, there is little modification to the general shape of the acceleration across most of the significant period range including the range of the statues' natural periods (less than 0.3 seconds). Specifically, for this example, the acceleration is reduced by nearly $50 \%$ in the range of the Colossi frequencies. It should be noted that this percentage might vary according to the amplitude of the input motion, as the sliding isolators will yield at accelerations in excess of the coefficient of friction. These and other test results support the use of a sliding isolation strategy for reducing the acceleration demands to statue systems. It should be noted that this experimental test was part of a much larger campaign studying the seismic response of tall, slender, eccentric structures in various configurations; and, additional details, results, and analyses regarding this experimental campaign can 
be found in Wittich and Hutchinson [14, 15].

\section{Conclusions}

The seismic response of cultural heritage statues is an important area needing further research, particularly given their irreplaceable nature and significant damage from recent earthquakes. Analyses of statues typically treat the boundaries as either completely free (freestanding or unattached) or as completely rigidly attached to the ground or floor. However, the assumption of total rigidity may not be adequate as drilling or modification to the statue is rarely, if ever, permitted. In an effort to quantify the dynamic characteristics of typical as-built statue systems, experimental modal analysis was conducted for six statues at the Asian Art Museum in San Francisco, California (USA). The measured natural frequencies ranged from $14 \mathrm{~Hz}$ (near-rigid) to $3 \mathrm{~Hz}$ (flexible). These low frequency modes characterize how rigidly the as-built statue-pedestal-restraint system is attached, as the first bending mode of the fixed-base statues would be significantly larger. The stiffest system consisted of simply embedding the base of the statue into a well-fitted pedestal. This system requires no modification, drilling, or epoxying of the statue; however, it does entail obstructing the view of a portion of the statue. Lateral restraint just below the mid-height of the statue was the most flexible horizontal restraint system tested. A comparison of these measured frequencies with the anticipated building response during earthquakes indicated a potential for significant excitation of the statues restrained in this manner. For these most vulnerable statues, a simple non-intrusive seismic isolation system was installed. The proposed isolation system consisted of a low-friction interface beneath the statue's pedestal, which was shown to markedly reduce the seismic accelerations transferred to the statue while having little frequency modification.

\section{Acknowledgments}

The experimental investigations presented were conducted through extensive collaboration with numerous organizations and individuals. The authors thank the Asian Art Museum of San Francisco for providing this unique opportunity, particularly Mr. Vincent Avalos. In addition, the authors thank Ms. Kim Cobb of the Museum Conservation Institute (Smithsonian Institute) as well as Don Clyde 
and Paul Segas of EQX Global. Information regarding the seismic retrofit of the Asian Art Museum

Furthermore, gratitude is extended to the Kingdom of Saudi Arabia for the rare opportunity to work closely with the Colossi sculptures. Funding for this study was provided through National Science Foundation under IGERT Award \#DGE-0966375, "Training, Research and Education in Engineering for Cultural Heritage Diagnostics,” and award \#CNS-1338192, “MRI: Development of Advanced Visualization Instrumentation for the Collaborative Exploration of Big Data." Additional support was provided by the Qualcomm Institute at UC San Diego, the Friends of CISA3, and the World Cultural Heritage Society. Additional assistance during the shake table tests was provided by the Charles Lee Powell Laboratory staff at UC San Diego, particularly Mr. Darren McKay. The continuous support of this project and guidance of Professor Falko Kuester is also greatly valued.

\section{References}

[1] F. Parisi, N. Augenti, Earthquake damages to cultural heritage constructions and simplified assessment of artworks, Eng. Fail. Anal. 34 (2013) 735-760.

[2] C.E. Wittich, T.C. Hutchinson, E. Lo, D. Meyer, F. Kuester, The South Napa earthquake of August 24, 2014: drone-based aerial and ground-based LiDAR imaging survey, Structural Systems Research Project Report SSRP-2014/09, University of California, San Diego, USA, 2014.

[3] J. Eaton (ed.), Overview report of the Nepal cultural emergency crowdmap initiative, International Centre for the Study of the Preservation and Restoration of Cultural Property, Rome, 2015.

[4] M.S. Agbabian, W.S. Ginell, S.F. Masri, R.L. Nigbor, Evaluation of earthquake damage mitigation methods for museum objects, Stud. Conserv. 36 (1991) 111-120.

[5] A. Borri, A. Grazini, Diagnostic analysis of the lesions and stability of Michelangelo's David, J. Cult. Herit. 7 (2006) 273-285.

[6] L. Berto, T. Favaretto, A. Saetta, F. Antonelli, L. Lazzarini, Assessment of seismic vulnerability of art objects: The "Galleria dei Prigioni” sculptures at the Accademia Gallery in Florence, J. Cult. Herit. $13(2012) 7-21$

[7] Y.D. Aktaş, A. Turer, Seismic evaluation and strengthening of Nemrut monuments, J. Cult. Herit. 
16 (2015) 381-385.

[8] M. Lowry, B.J. Farrar, D. Armendariz, J. Podany, Seismic mount making: a review of the protection of objects in the J. Paul Getty Museum from earthquake damage, in: J. Podany (Ed.) Advances in the protection of museum collections from earthquake damage, Getty Publications, Los Angeles, CA, 2008.

[9] S. Tuholski, P. Rodler, San Francisco's new Asian Art Museum, in: Proceedings of the $13^{\text {th }}$ World Conference on Earthquake Engineering, Vancouver, 2004 (Paper No. 2339).

[10] International Code Council (ICC), Report No. AC156: Acceptance criteria for seismic qualification by shake table testing of nonstructural components and systems, ICC, Whittier, CA, 2007.

[11] V. Lambrou, M.C. Constantinou, Study of seismic isolation systems for computer floors, Technical Report MCEER 94-0020, State University of New York at Buffalo, Buffalo, NY, USA, 1994.

[12] M. Hamidi, M.H. El Naggar, On the performance of SCF in seismic isolation of the interior equipment of buildings, Earthquake Eng. Struct. Dyn. 36 (2007) 1581-1604.

[13] P.S. Harvey, G.-P. Zéhil, H.P. Gavin, Experimental validation of a simplified model for rolling isolation systems, Earthquake Eng. Struct. Dyn. 43 (2014) 1067-1088.

[14] C.E. Wittich, T.C. Hutchinson, Shake table tests of stiff, unattached, asymmetric structures, Earthquake Eng. Struct. Dyn. 44 (2015) 2425-2443.

[15] C.E. Wittich, T.C. Hutchinson, Shake table tests of stiff, unattached, asymmetric structures phase 2: pedestal-mounted, Structural Systems Research Project Report SSRP-2015/05, University of California, San Diego, USA, 2015. 
Historical and physical attributes for each of the tested statues.

\begin{tabular}{|c|c|c|c|c|c|c|c|}
\hline Statue & Date & Origin & Material & $\begin{array}{l}\text { Restraint } \\
\text { Description }\end{array}$ & $\begin{array}{l}\text { Mass } \\
{[\mathrm{kg}]}\end{array}$ & $\begin{array}{l}\text { Statue } \\
\text { Height [m] }\end{array}$ & $\begin{array}{l}\text { Height of Lateral } \\
\text { Restraint [m] }\end{array}$ \\
\hline Colossi 111 & $\begin{array}{l}4^{\text {th }}-3^{\text {rd }} c . \\
B C E\end{array}$ & $\begin{array}{l}\text { Saudi } \\
\text { Arabia }\end{array}$ & $\begin{array}{l}\text { Sandstone } \\
\text { (monolithic) }\end{array}$ & $\begin{array}{l}\text { (2) contoured arms } \\
\text { along height; } \\
\text { custom-mold base }\end{array}$ & 1100 & 2.48 & 0.95 \\
\hline Colossi 112 & $\begin{array}{l}4^{\mathrm{th}}-3^{\mathrm{rd}} \mathrm{c} . \\
\mathrm{BCE}\end{array}$ & $\begin{array}{l}\text { Saudi } \\
\text { Arabia }\end{array}$ & $\begin{array}{l}\text { Sandstone } \\
\text { (monolithic) }\end{array}$ & $\begin{array}{l}\text { (2) contoured arms } \\
\text { along height; } \\
\text { custom-mold base }\end{array}$ & 725 & 1.98 & 0.40 \\
\hline Colossi 113 & $\begin{array}{l}4^{\mathrm{th}}-3^{\mathrm{rd}} \mathrm{c} \\
\mathrm{BCE}\end{array}$ & $\begin{array}{l}\text { Saudi } \\
\text { Arabia }\end{array}$ & $\begin{array}{l}\text { Sandstone } \\
\text { (monolithic) }\end{array}$ & $\begin{array}{l}\text { (2) contoured arms } \\
\text { along height; } \\
\text { custom-mold base }\end{array}$ & 700 & 2.25 & 0.95 \\
\hline Bodhisattva & $\begin{array}{l}10^{\text {th }}-11^{\text {th }} \mathrm{c} . \\
C E\end{array}$ & China & $\begin{array}{l}\text { Marble } \\
\text { (monolithic) }\end{array}$ & $\begin{array}{l}\text { embedded epoxy } \\
\text { anchor tensioned at } \\
\text { base via turnbuckle }\end{array}$ & 850 & 2.16 & 0.0 \\
\hline Rama & $\begin{array}{l}14^{\text {th }}-16^{\text {th }} c . \\
C E\end{array}$ & India & $\begin{array}{l}\text { Granite } \\
\text { (monolithic) }\end{array}$ & $\begin{array}{l}\text { embedded base } \\
\text { within pedestal }\end{array}$ & 550 & 2.69 & 0.0 \\
\hline Attendant & $\begin{array}{l}15^{\text {th }}-16^{\text {th }} \mathrm{c} . \\
C E\end{array}$ & China & $\begin{array}{l}\text { Iron } \\
\text { (monolithic) }\end{array}$ & $\begin{array}{l}\text { (3) contoured clips } \\
\text { at base }\end{array}$ & $<100$ & 1.35 & 0.0 \\
\hline
\end{tabular}




\section{Figure Captions}

Fig. 1. Tested statues at the Asian Art Museum from (a-c) the Roads of Arabia exhibit, and (d-f) the primary museum collections.

Fig. 2. Images and drawings detailing the restraint mechanisms of each of the tested statues. Note that the restraint system was typical across the Colossi statues.

Fig. 3. Sensor placement for a sample test along statue and restraint system: (a) Colossi 112 with 7 accelerometers attached and wrapped polyethylene beneath (b) rubber bands securing the sensors to the specimen; (c) magnetic tips were used to secure the sensors to steel posts; and, (d) hammer tap at a relatively flat surface at the top of the statue.

Fig. 4. Magnitude of the frequency response function (FRF) for each sensor on Colossi 112.

Fig. 5. First two natural frequencies of each of the tested statue-restraint systems.

Fig. 6. (a) Frequency response function of Colossi 111 in its as-built configuration overlaid with that of the restraint system loosened. (b) Ratio of the natural frequencies of the loosened system to that of the as-built system for Colossi 111 and Colossi 112.

Fig. 7. Design floor response spectrum (digitized from: Tuholski and Rodler [9]) overlaid with the first modes of the Colossi statues and the primary gallery statues (5\% damped). 
Fig. 8. (a) Schematic of the low-friction sliding plate isolation system. (b) Photograph of the installed isolation system beneath Colossi 111. (c) Experimental setup for shake table testing of the isolation system beneath a restrained statue-pedestal system.

Fig. 9. Experimental results for the isolated system overlaid with that atop a typical marble interface: (a) acceleration time history of the pedestal, and (b) pseudo-spectral acceleration measured at the top of the pedestal and top of the shake table assuming $5 \%$ damping (motion from the 1999 Duzce Earthquake recorded at Bolu station in Turkey, see [14] for additional information). 


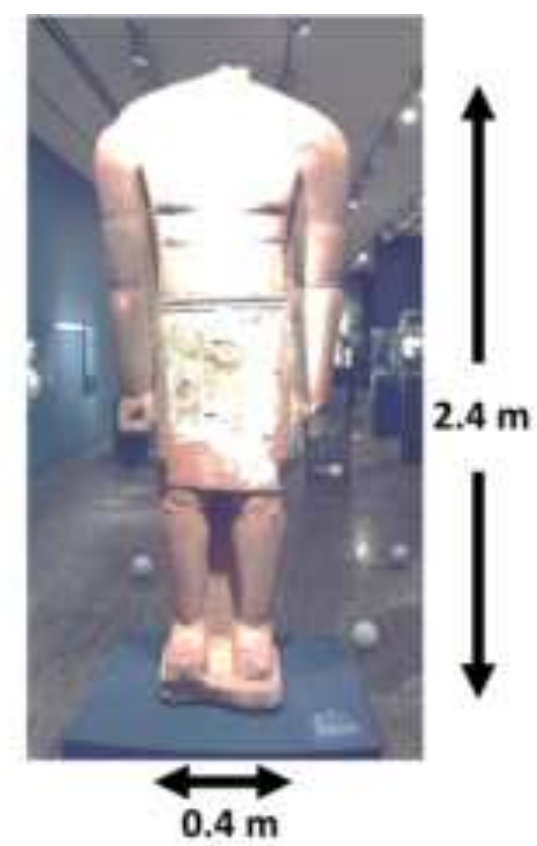

(a) Colossi 111

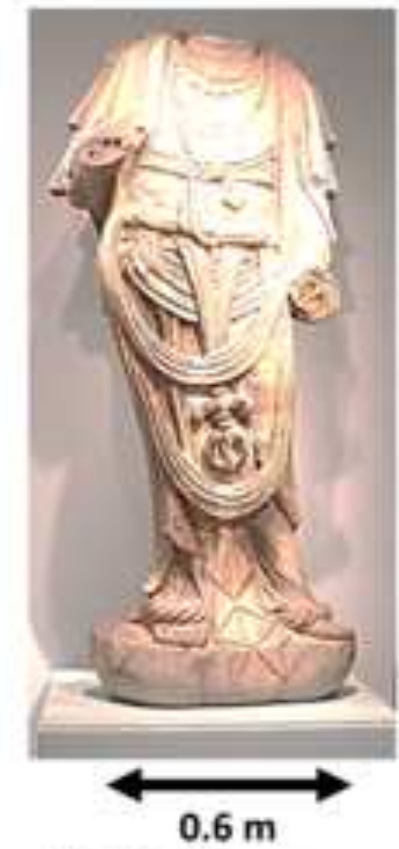

(d) Bodhisattva

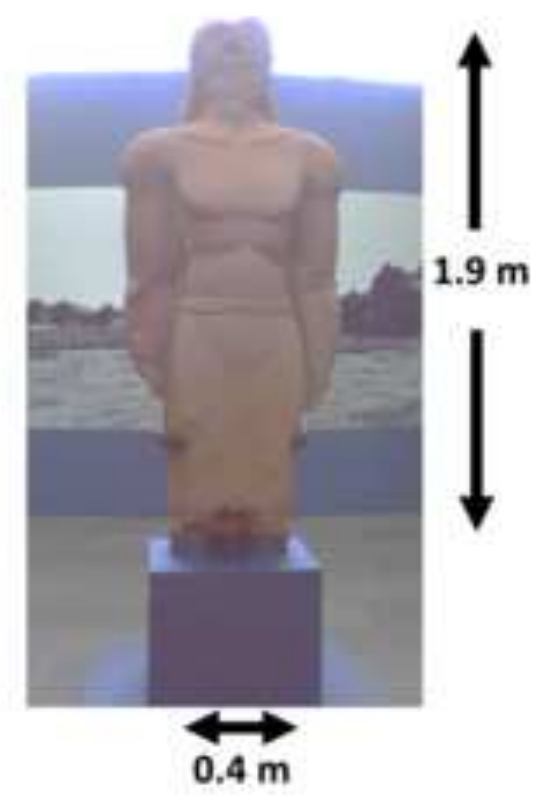

(b) Colossi 112

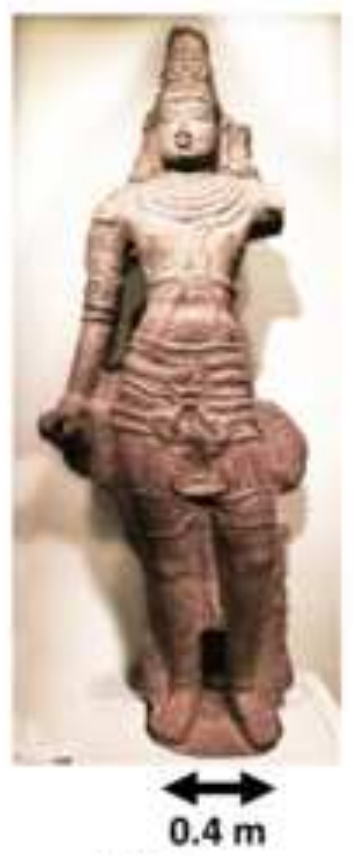

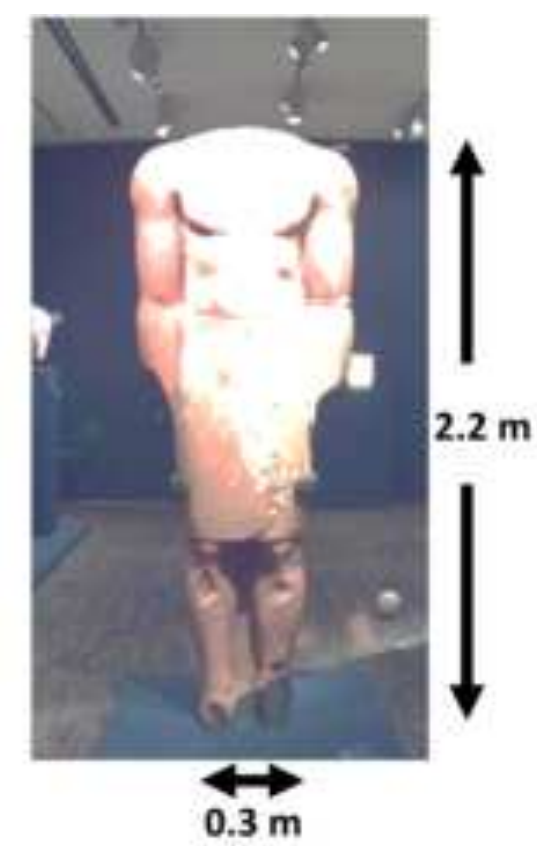

(c) Colossi 113

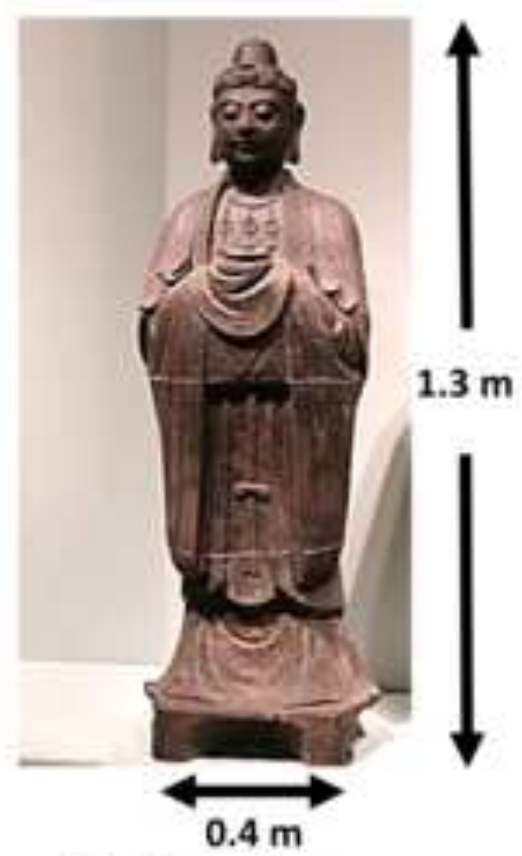

(f) Attendant (e) Rama

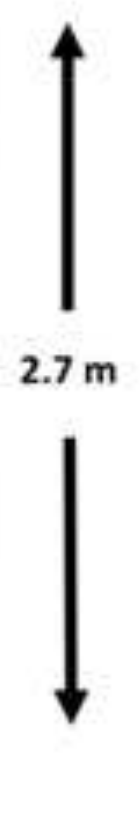

$.7 \mathrm{~m}$

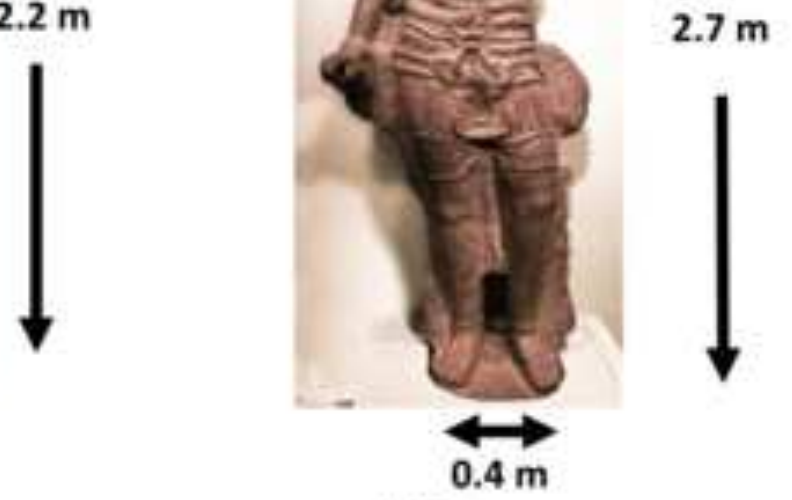

(e) Roma 


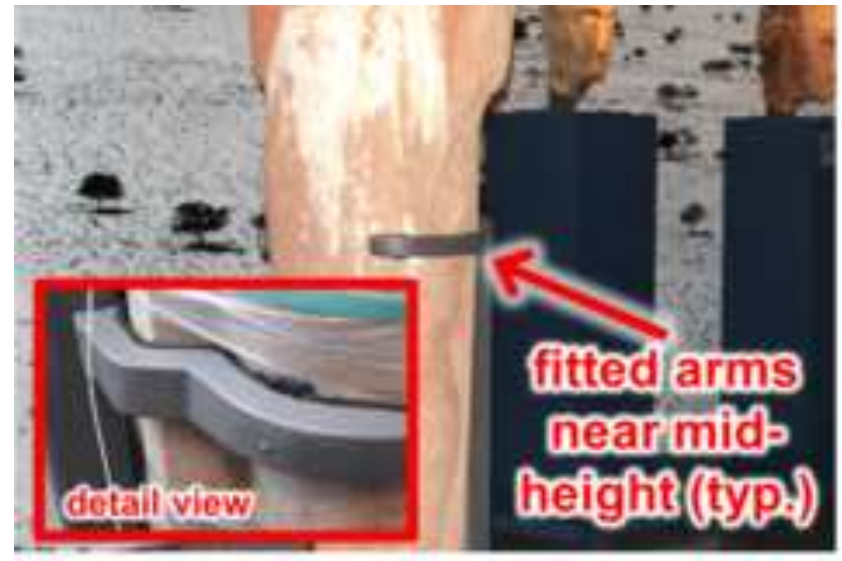

(a) Colossi 111

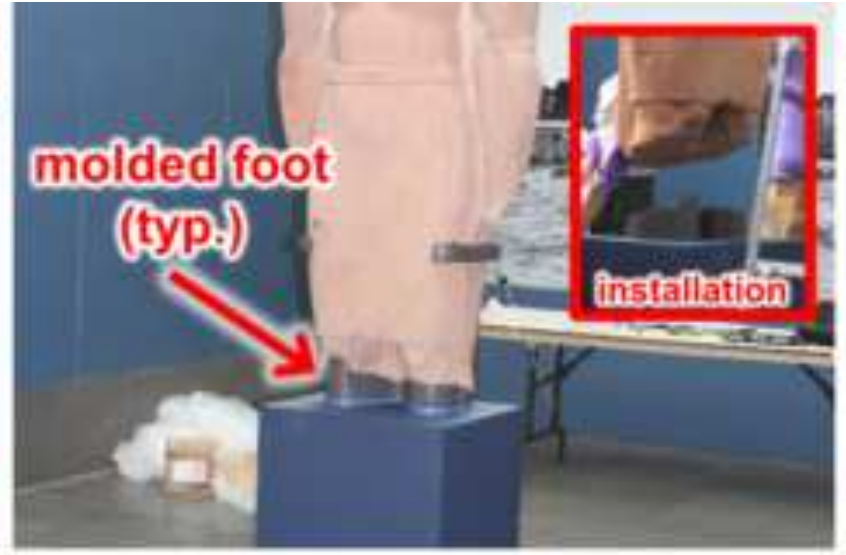

(b) Colossi 112

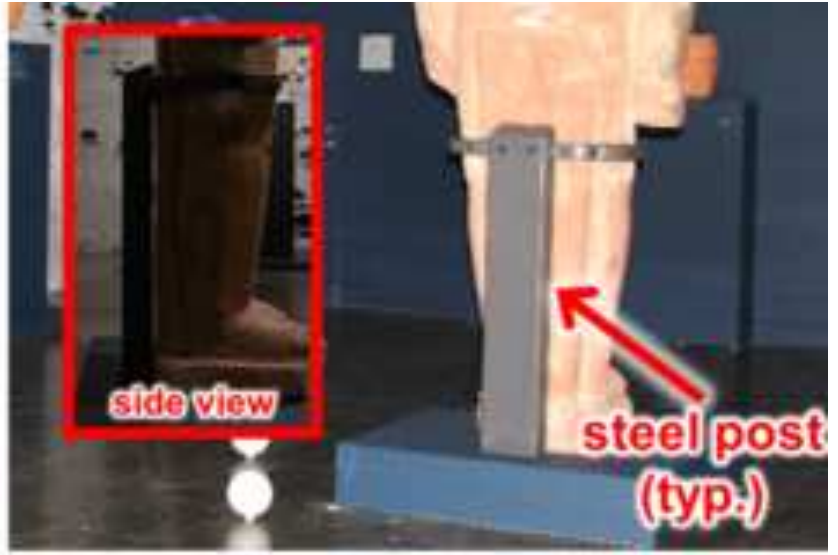

(c) Colossi 113

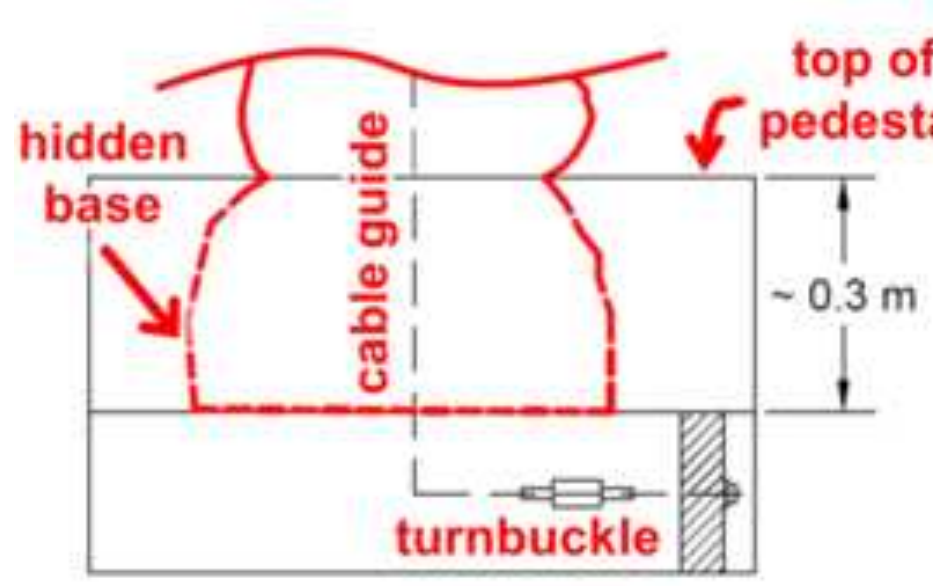

(d) Bodhisattva

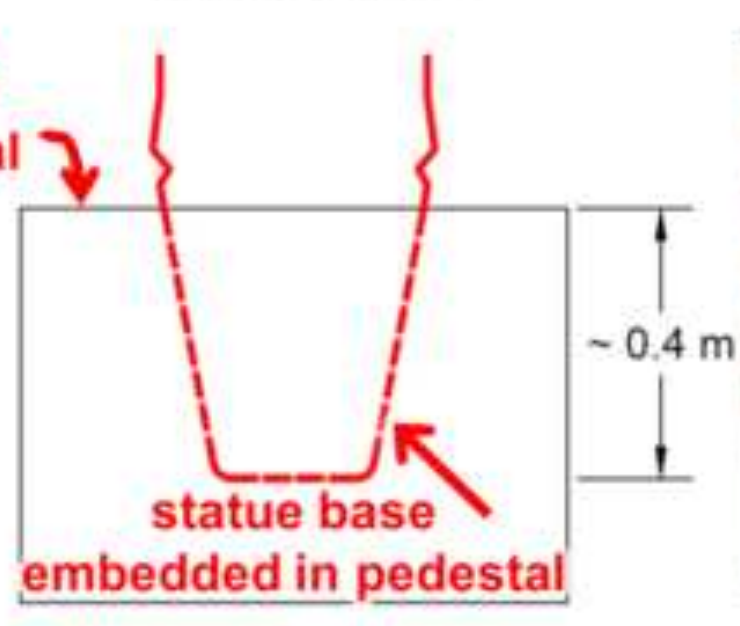

(e) Rama

\section{embedded in pedestal}

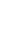

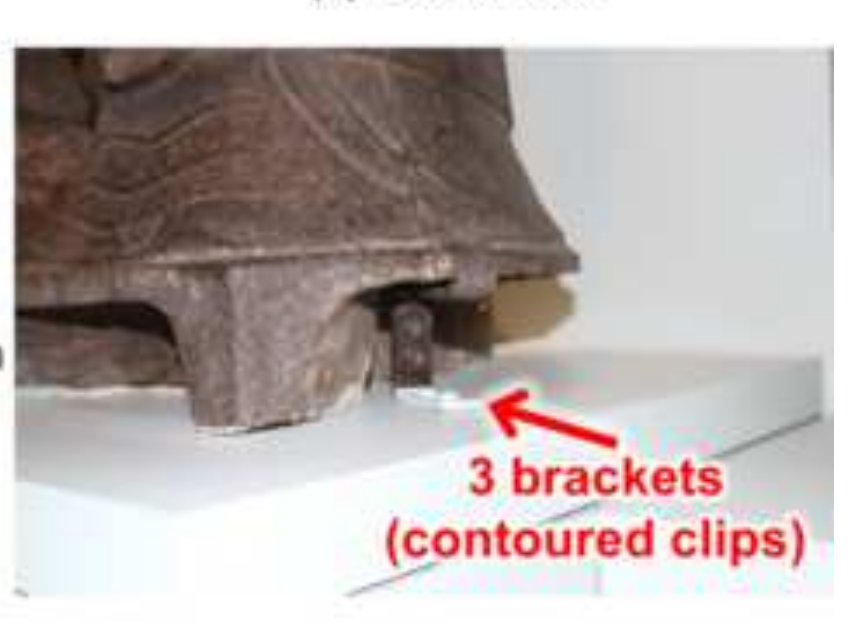

(f) Attendant 
(a)
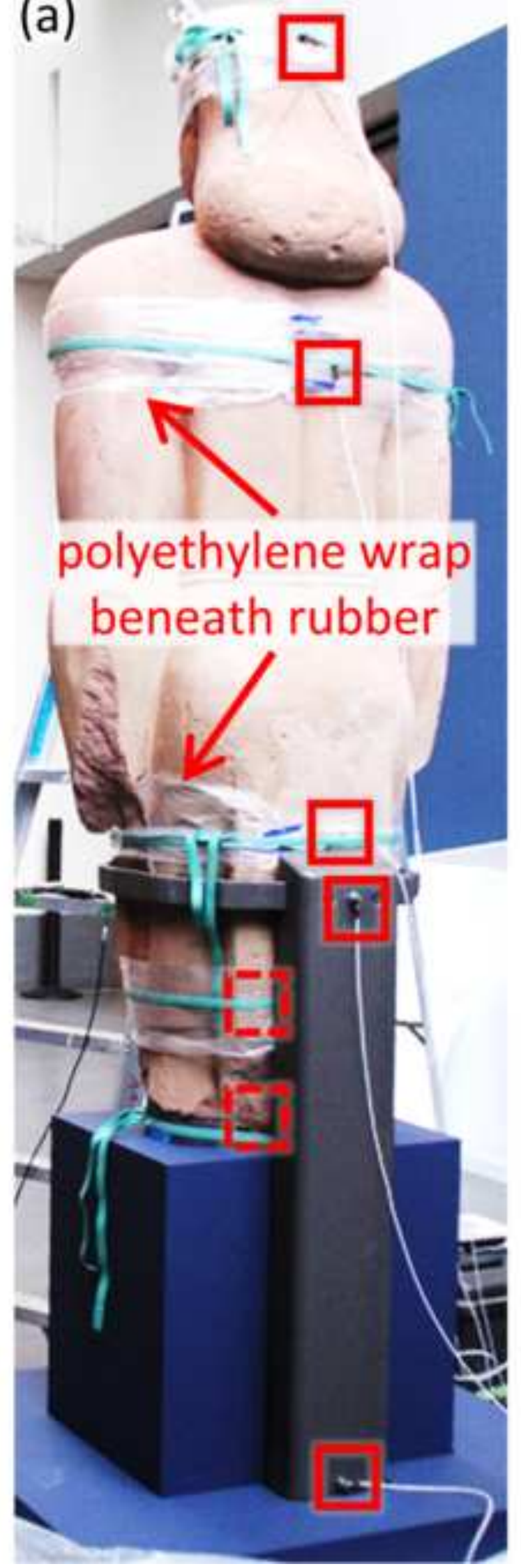
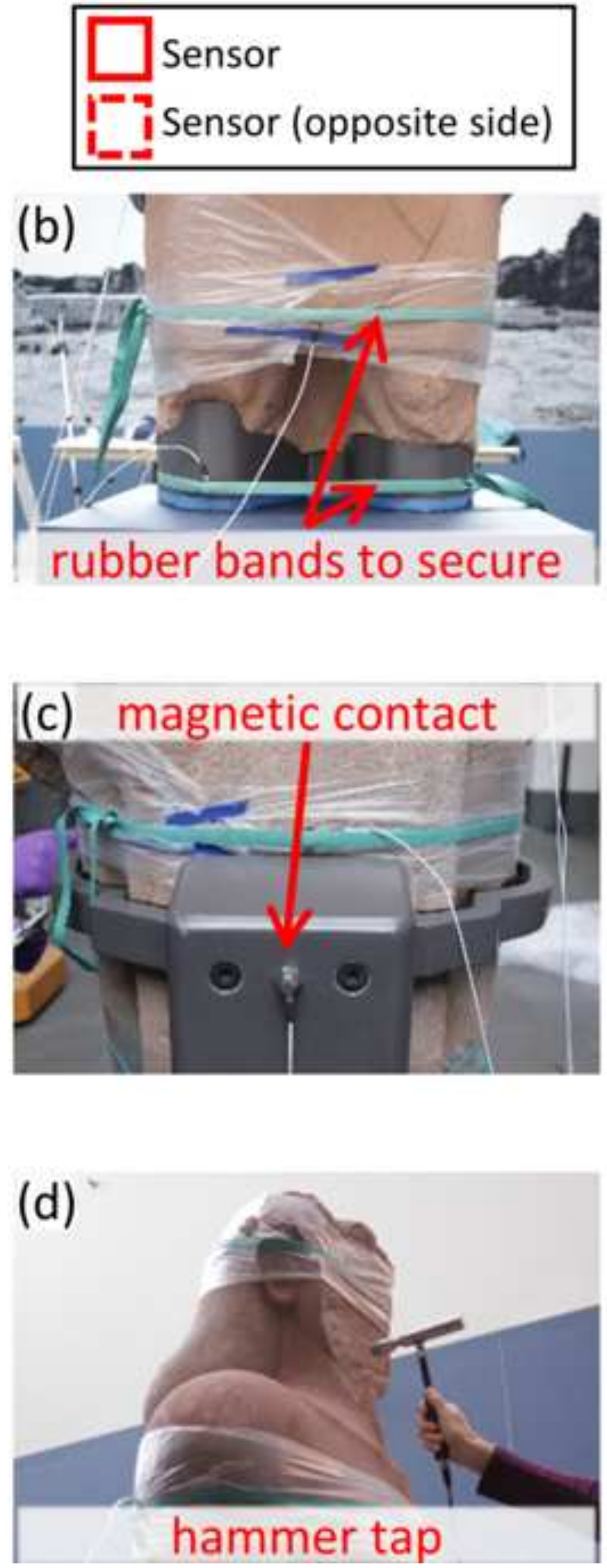


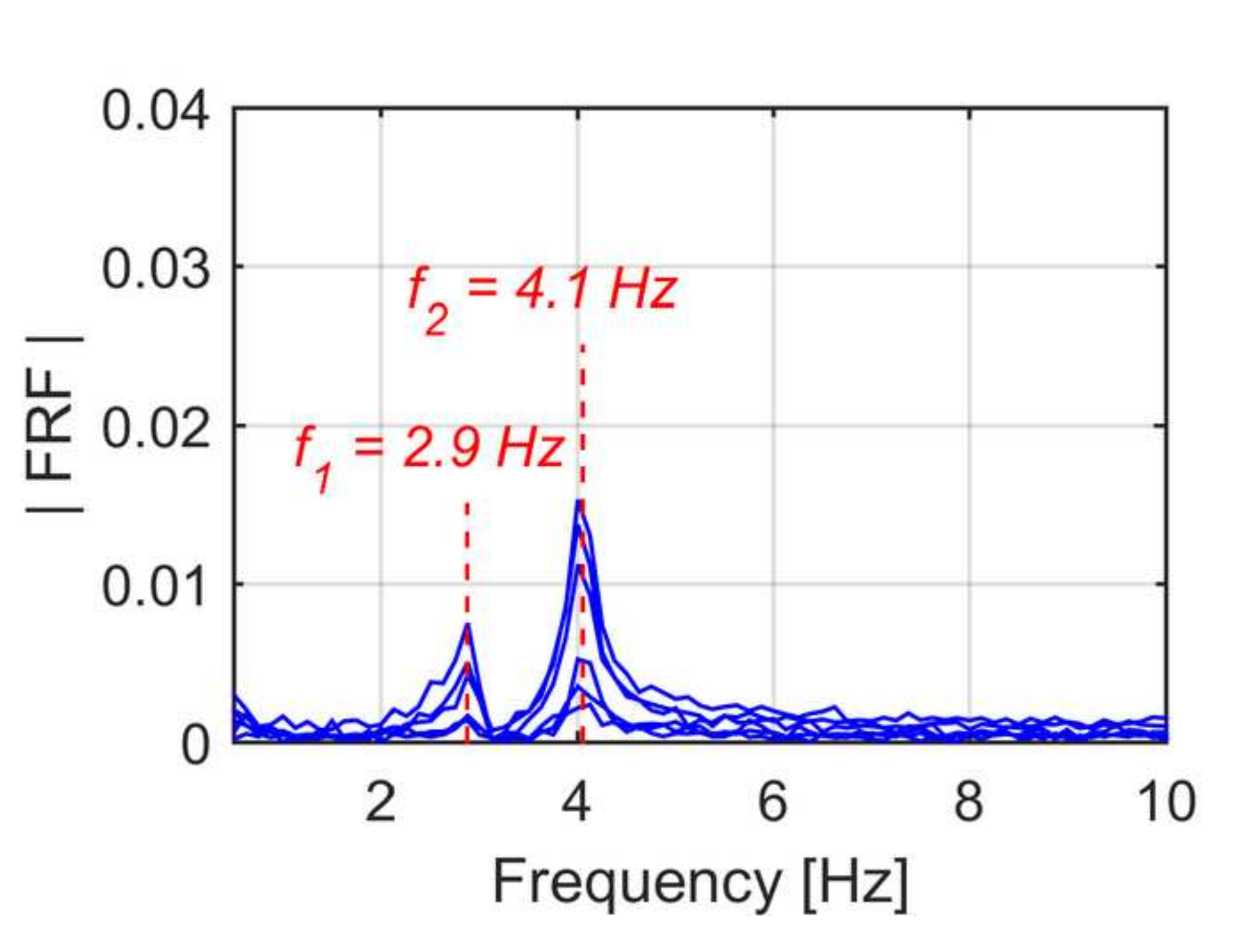

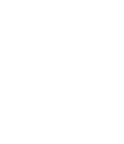

列 

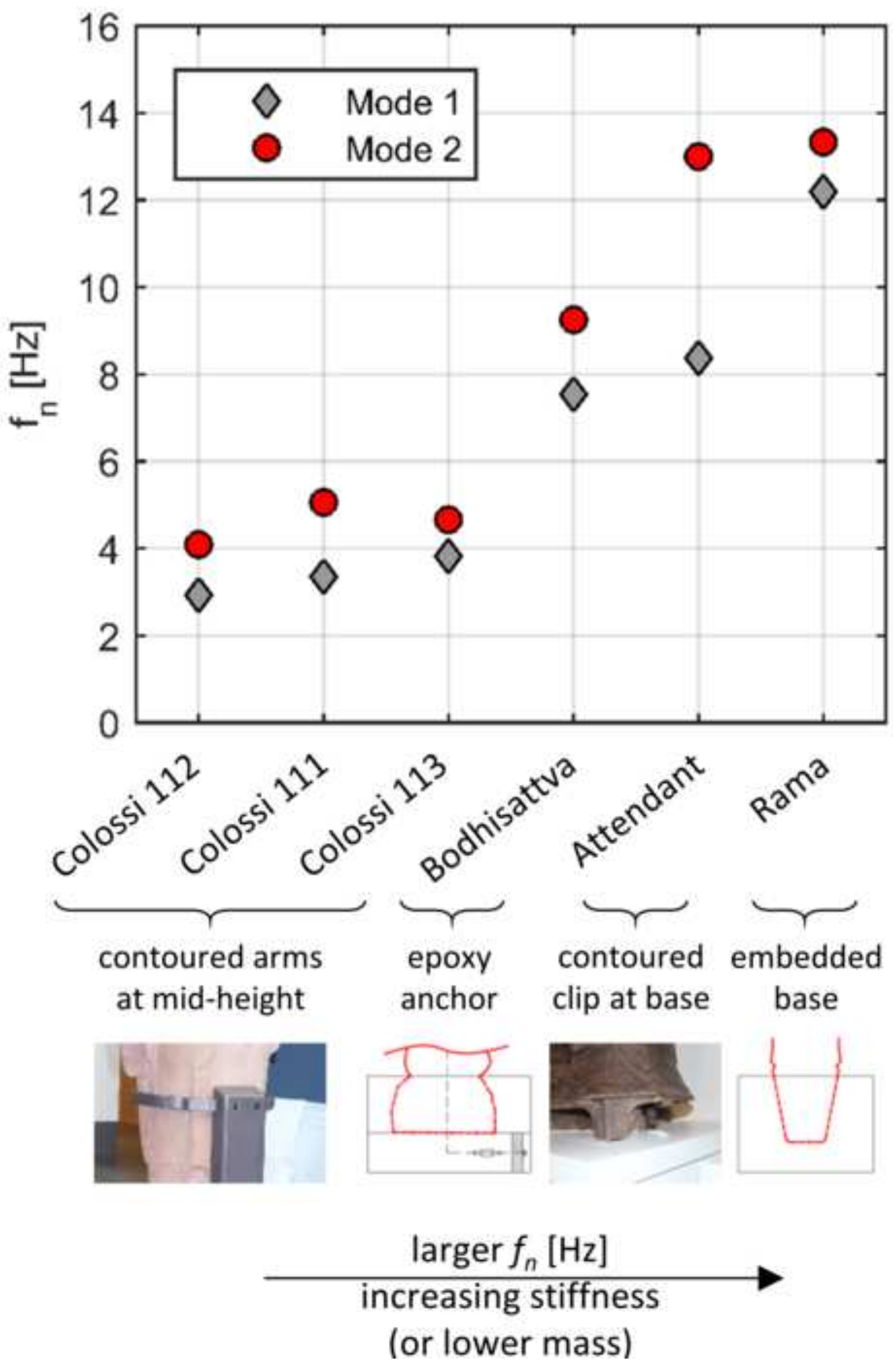

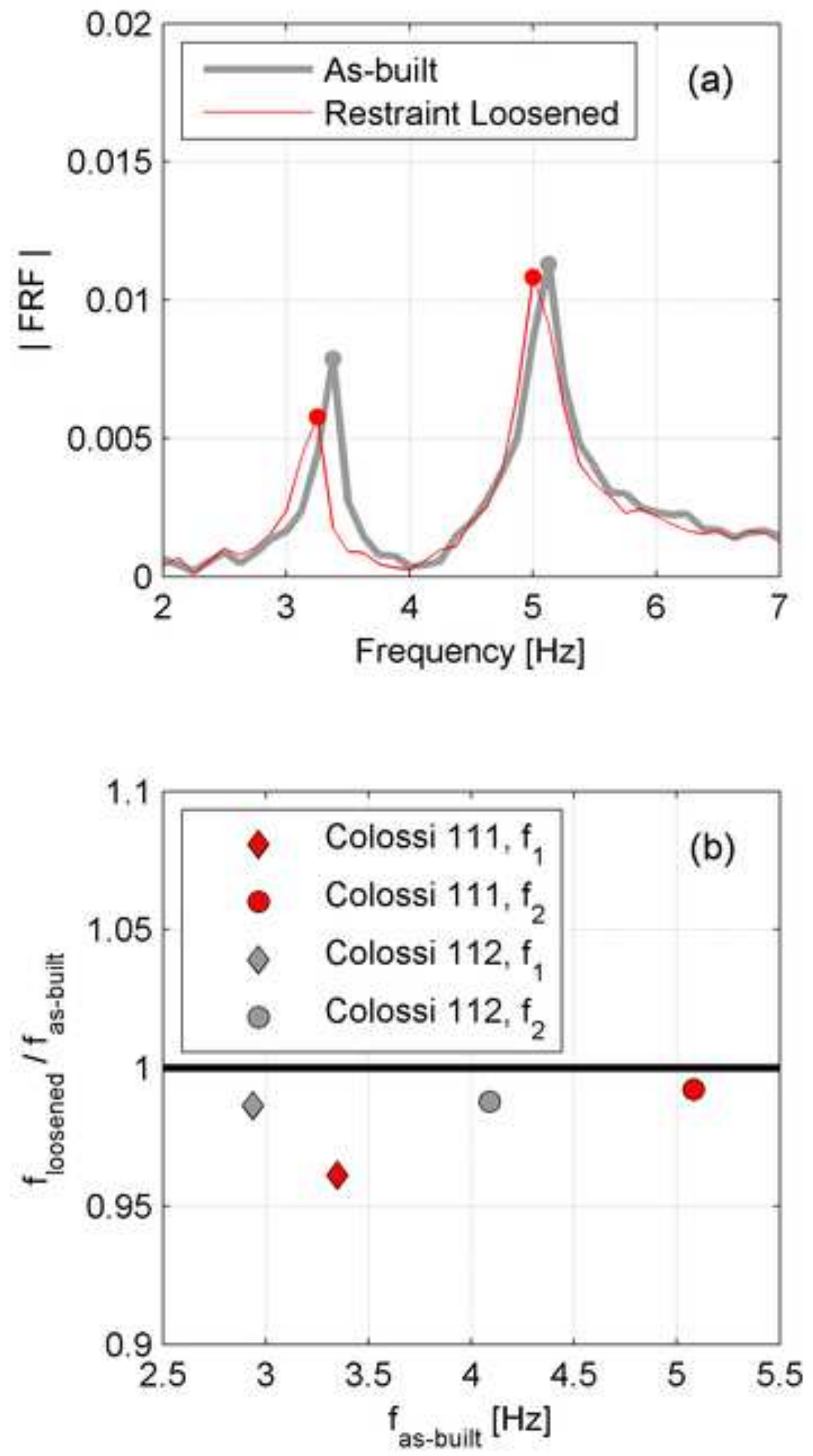


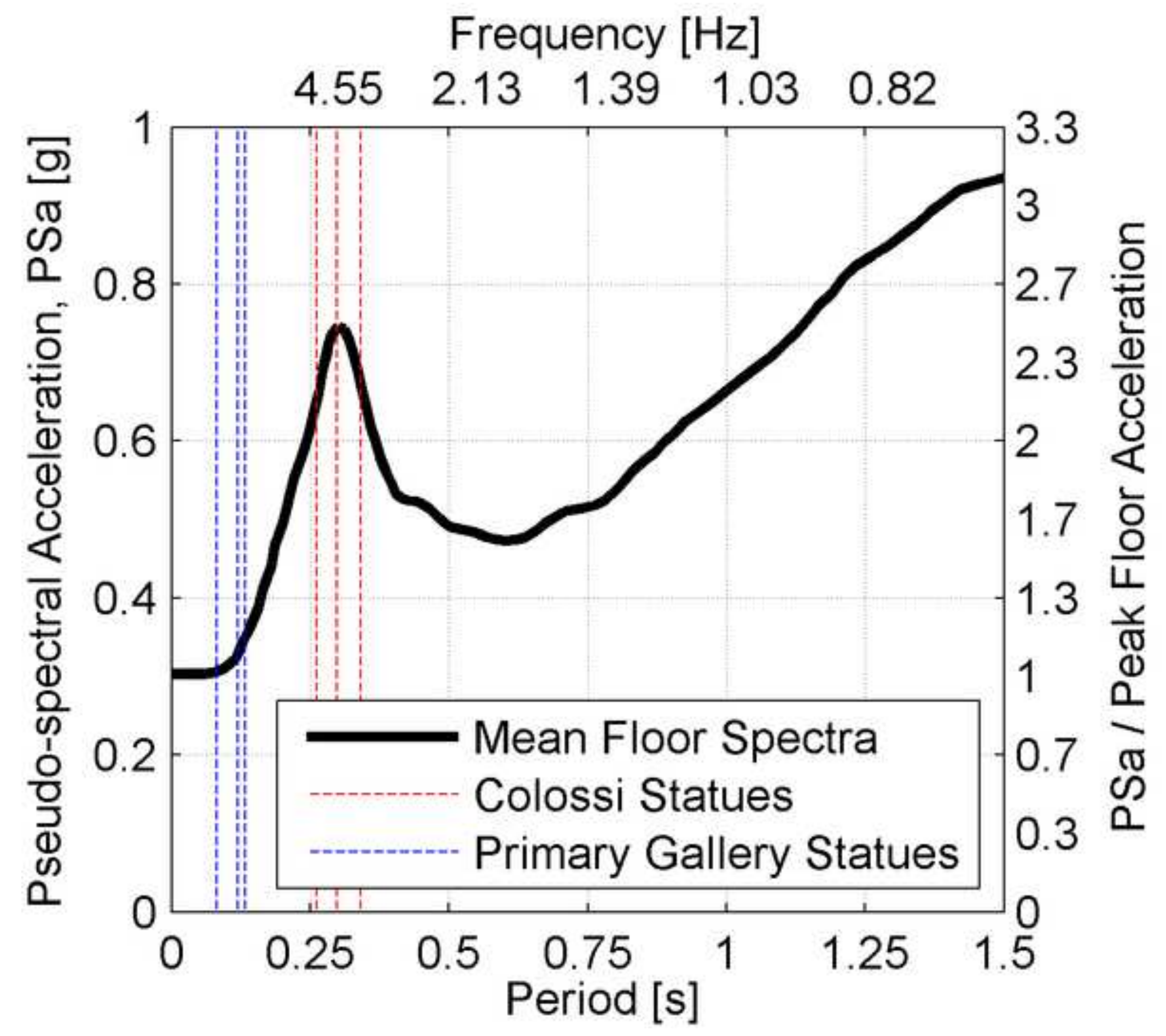




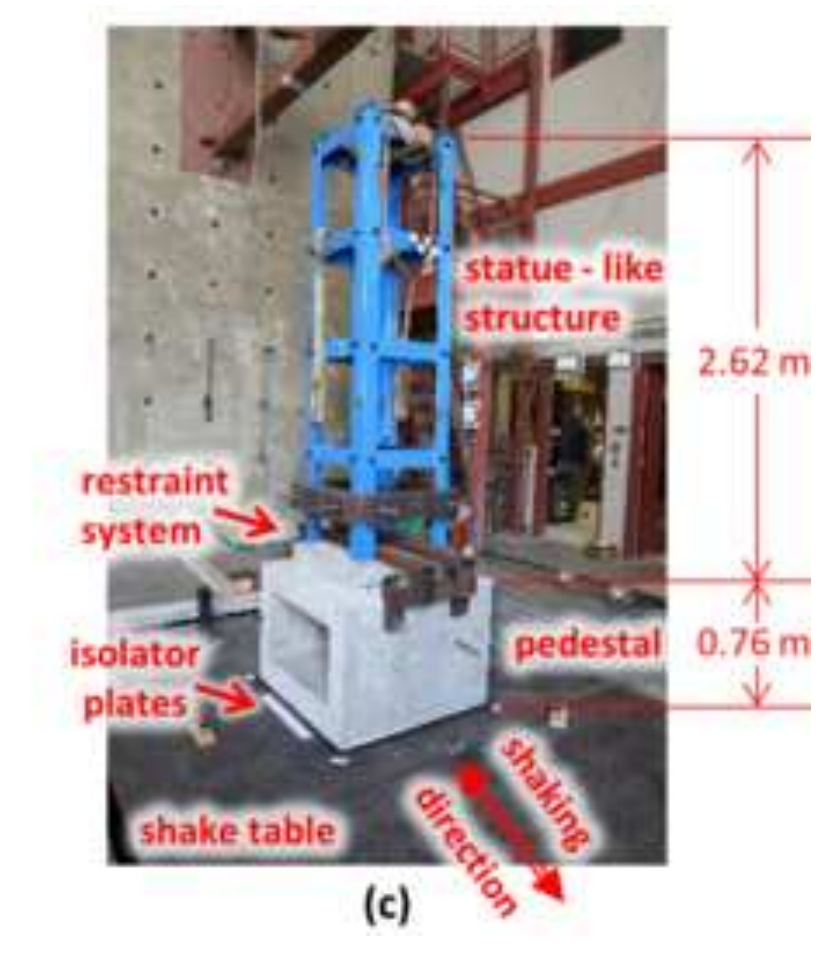

(c) (a)

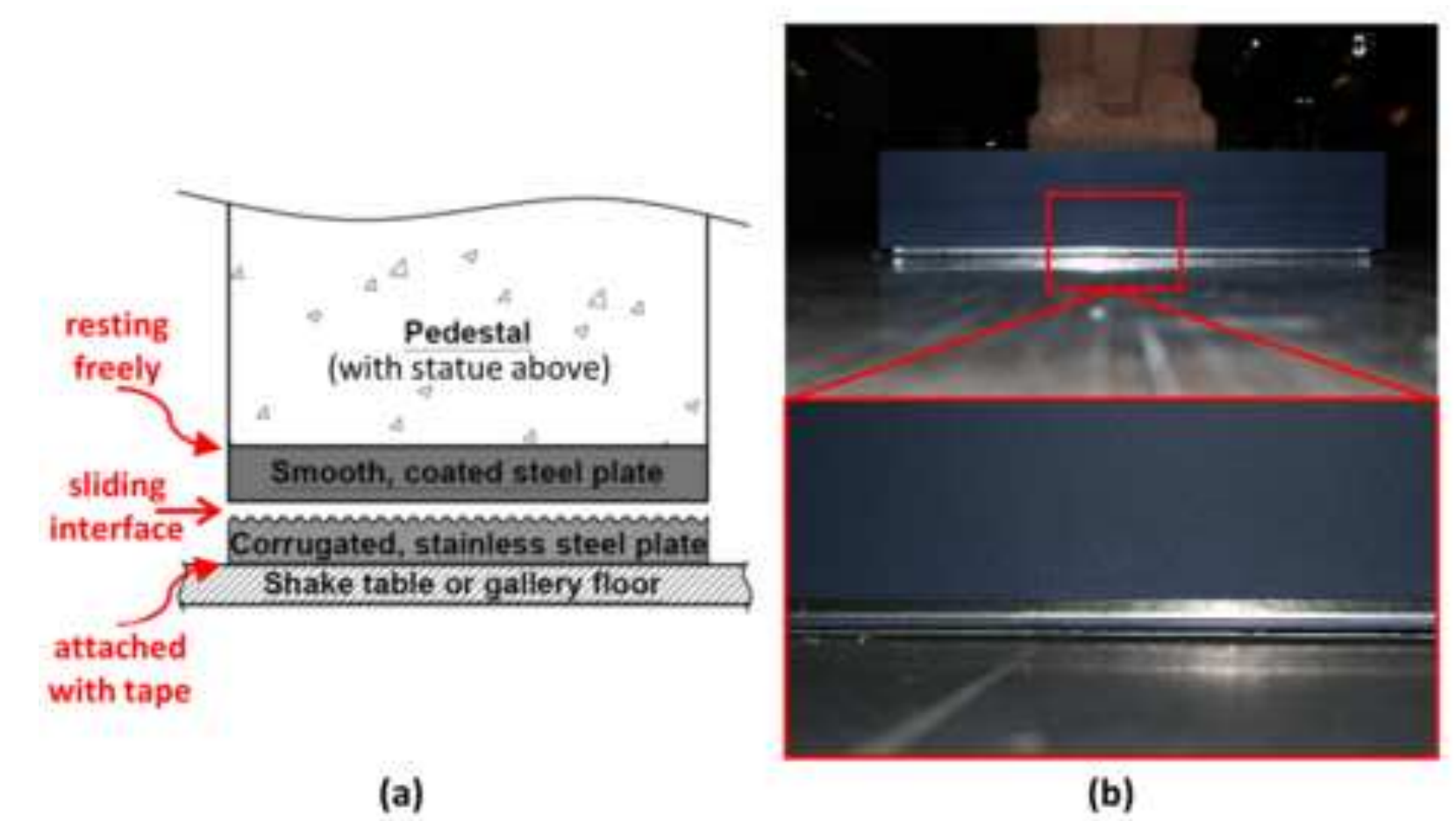

(b)

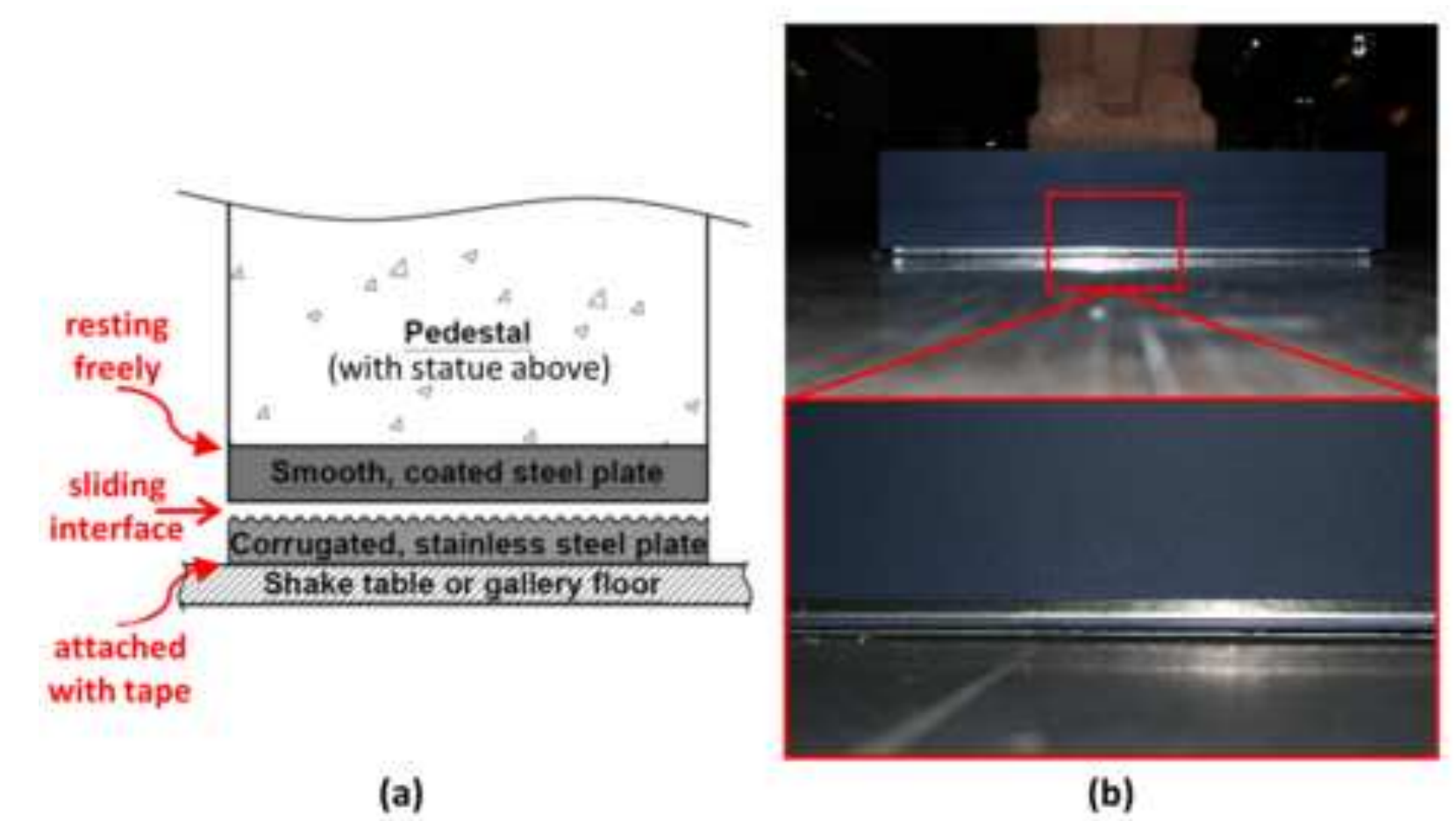

(1)

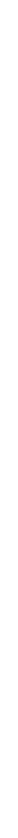

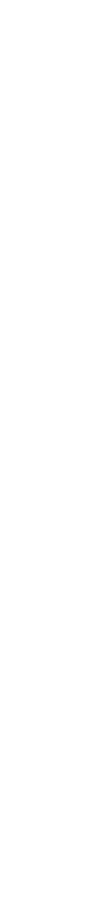




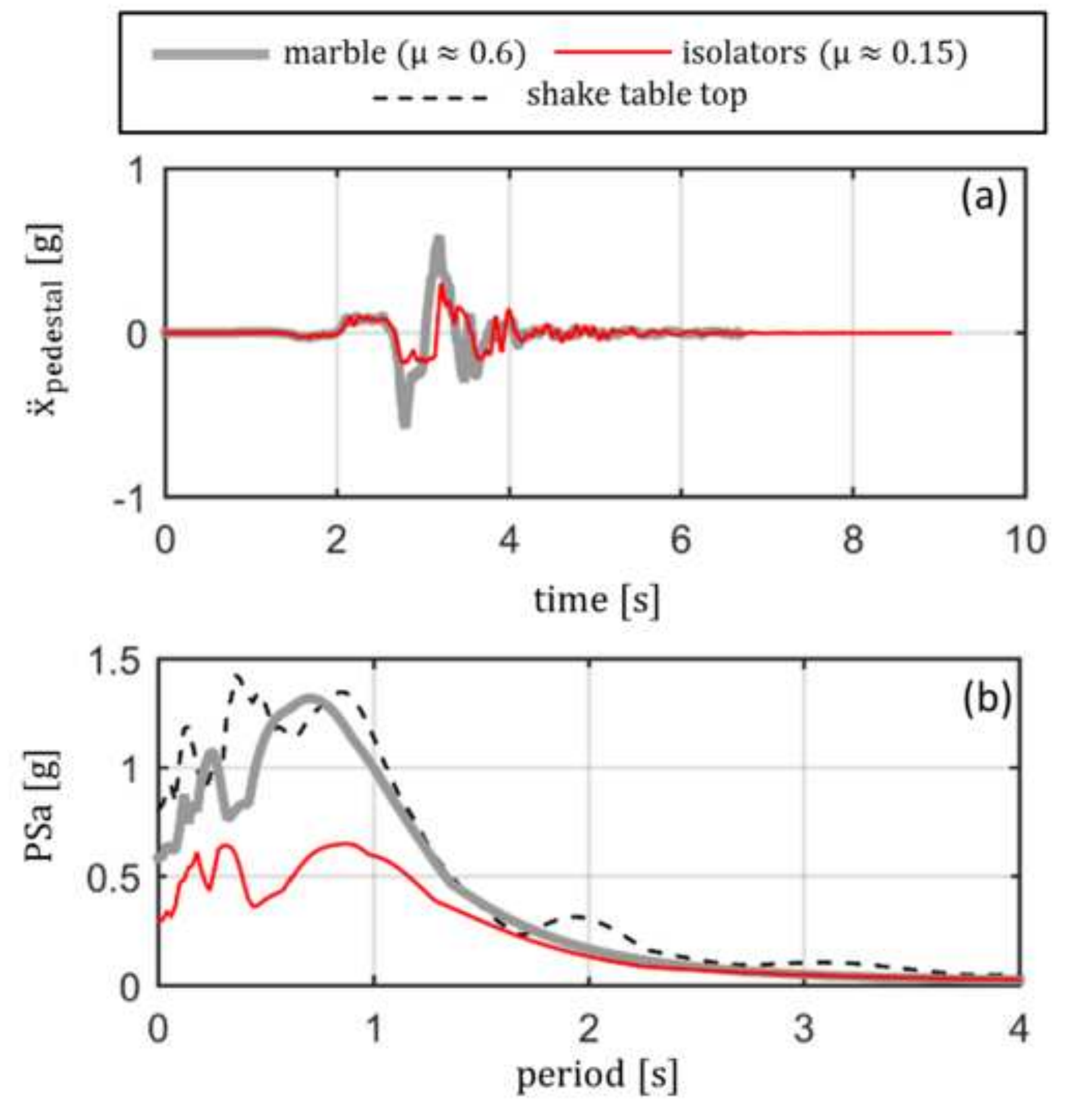

Figure 9

- - - - shake table top

time [s]

0

(a) 4

$$
\text { . }
$$

